\title{
Infection Control Measures among Healthcare Workers: Knowledge, Attitude and Practice
}

\author{
Emmanuel Gasaba' ${ }^{1}$, Jonathan Niciza', Daniel Muhayimana ${ }^{1}$, Edouard Niyongabo ${ }^{1,2 *}$ \\ ${ }^{1}$ Hope Africa University, faculty of Health Sciences, Master of Science in Nursing, BI-Bujumbura, Burundi \\ ${ }^{2}$ National Institute of Public Health, Department of Public Health Sciences, Bujumbura, Burundi \\ Email: *niyongaboedouard@gmail.com
}

How to cite this paper: Gasaba, E., Niciza, J., Muhayimana, D. and Niyongabo, E. (2020) Infection Control Measures among Healthcare Workers: Knowledge, Attitude and Practice. Open Journal of Nursing, 10, 1068-1080.

https://doi.org/10.4236/ojn.2020.1011076

Received: August 24, 2020

Accepted: November 24, 2020

Published: November 27, 2020

Copyright $\odot 2020$ by author(s) and Scientific Research Publishing Inc. This work is licensed under the Creative Commons Attribution International License (CC BY 4.0).

http://creativecommons.org/licenses/by/4.0/

\begin{abstract}
Background: Nosocomial infections are some of public health problems globally and continue to be increased regardless of the hospital's efforts on infection control measures and are contributing significantly to morbidity, mortality and cost. The absence of infection control policies, guidelines and trained professionals also contributes to the magnitude of the problem. The aim of this study was to assess the Knowledge, attitude and practices towards infection control measures among healthcare workers at Old Mutare Hospital. Methods: A cross-sectional survey design was used to acquire information. A purposive sampling method was used to select 22 nurses, 15 nurse Aids and 2 laboratory technicians (Lab Tech). A self-administered questionnaire with four components addressing demographic data, knowledge, attitudes and practices was used to collect data that was completed by a checklist. Results: The study findings revealed a poor knowledge of infection control measures among the nurse's aide. The attitude and practices among participants were impartially good in all variables. The participants had scored over $50 \%$ towards their attitude and their practices on infection control. A significant statistical difference was found between the professional status of the participants and the ability to explain how one can get Hospital Acquired Infections (HAIs) and awareness of infection control programs in their hospital $\left(\mathrm{r}_{\mathrm{s}}=0.640,0.645\right)$ with $\mathrm{P}<0.05$ (0.01, 0.01) respectively. Conclusion: Despite of having a fair attitude and practice towards infection control, the participants had presented poor knowledge; therefore, it had been recommended that in service training and workshop should be planned by the administration to update their knowledge and attain full compliance towards their practice.
\end{abstract}

\section{Keywords}

Infection Control, Hospital Acquired Infections, Nurse, Nurse's Aide, Laboratory Technicians 


\section{Introduction}

Normally healthcare workers were supposed to excel for numerous measures on infection control to be protected and protect their patients. The lack of Knowledge and the malpractice of healthcare workers in the health sector has been the common observed and been the source of nosocomial infections.

Nosocomial infections are some of the public health problems globally and continue to increase regardless of the hospital's efforts on infection control measures and are contributing significantly to morbidity, mortality and cost.

The WHO had declared that nosocomial infections would never be found in the hospitals once adequate infection control practice is carried out. The absence of infection control policies, guidelines and trained professionals also enhance the magnitude of the problem.

Nosocomial infections are infections acquired in the hospital or other health care facilities that were not present or incubating at the time of the client's admission. It consists of those infections that are symptomatic after the discharge of the client as well as those among medical personnel.

\section{Background}

The research has been conducted at Old Mutare Hospital (OMH) located in Mutasa District of Manicaland province in Zimbabwe for the achievement of the requirements of the bachelor honors degree of sciences in nursing.

The annual epidemiological report of communicable diseases in US, revealed that one out of seven hospital-acquired infections (HAIs) leads to death of $14 \%$ compare with the Europe the number of 1 out 122 only, or a simply $0.8 \%$. Refer to the overall estimates on the attributable mortality of nosocomial infections by the US CDC around 37,000 deaths (0.9\%) are caused automatically by nosocomial infections every year. On the other hand, the EU reports 111,000 deaths. Nosocomial infections are attached also with an extra day hospital stay of 16 million every year, which create a considerable cost and a significant burden for healthcare systems.

Study done in the two hospitals in Kenya showed the prevalence of nosocomial infection was $12.03 \%$ with Ukwala Sub County Hospital (USCH) recording 5.6\% while Matibabu Foundation Hospital in Ugenya Sub County (MFK) had $6.5 \%[1]$.

Nosocomial infections continue to be the major cause of death in Zambia, with consequences to the government to contribute more figures on the healthcare budget of (57.5\%) [2].

Most of the factors that contribute to the magnitude of the problem in several African countries include the overcrowding and understaffing in the hospitals which leads to poor infection control practices. Lack of infection control policies, guidelines and trained professionals contribute to the extent of the problem.

Referrer to the African Conference on Infection Prevention control (2009), reported that nosocomial infections in Africa are commonly urinary tract infec- 
tions, surgical site infections, hospital acquired pneumonia and health care associated septicemia. It had reported that in 2009, the World Health Organization estimate $5 \%-10 \%$ of patients acquired one or more infection in health facilities, with the risk of 2 - 10 times higher in developing countries [3].

Admissions for hospital acquire infection and the predisposition to infection has been connected to the use of invasive devices and negligent infection control practice contributing to the necessity of implementing control measures [4].

Old Mutare Hospital face also some of these challenges such as lack of infrastructure where I found six beds in a small room of $6 \mathrm{~m} \times 4 \mathrm{~m}$, and a mixture of children from all types of ages grouped in that small room which can lead to the transmission of infection very easily. Moreover, financial challenge has been highlighted also where a lack of necessary material needed to control the infection in that hospital. Thus, this research aimed to assess the knowledge, attitude and practice towards infection control measures among healthcare workers at old Mutare hospital.

A descriptive survey design was employed to explore the following question:

1) What is the level of employees' understanding on infection control measures at $\mathrm{OMH}$ ?

2) What are the attitudes of OMH healthcare workers towards infection control measures?

3) Are there policies and guidelines put in place to prevent nosocomial infections? If yes, are the healthcare workers aware them?

4) Is the tools use on infection control measures available? If yes, are the healthcare workers knowledgeable of their use?

\section{Conceptual Framework}

The study was oriented on the environmental theory of Florence Nightingale on infection control. The theory explains the important of carrying out infection control measures such as damp dusting, use of sterile technique during procedures and use of personal protective equipment. Nightingale was the first nurse to identify the relationship between nursing and infection control. She comes out with her philosophy of improving hygiene conditions to reduce the mortality cases as the conditions in the hospitals were terrible. Lawrence, chairperson of the infection control nurses association (ICNA) believed that Nightingale was probably the first infection control nurse without actually realizing it. Nowadays nurses play a key role to ensure the survival of infection control practices. This would happen by maintaining proper infection control, sterile technique principles as well as continuous education on infection control through in-service training and induction courses [3].

\section{Methods}

The participant in this study were nurses, nurse-aid and Lab Tech working at OMH in January 2018, a United Methodist Church institution located in Mutasa 
District of Manicaland province, in the eastern part of Zimbabwe. A Cross sectional survey design was used to acquire information. The hospital superintendent argue that the institution had a staffs' shortage, thus a purposive sampling method was used to select the 39 healthcare workers (nurses, nurse-aids and Lab Tech) among the 43 who work at $\mathrm{OMH}$ as they were the most ones dealing with infections control of the patients, therefore Doctors, anesthetist, Dentist, pharmacist, cleaners, the food handlers were not included in this study. Old Mutare Hospital serves a catchment population of about 15000, mainly from surrounding farms, nearby rural areas, schools and Africa University, which driven me to assess the infection control measures.

A self-report method involving questionnaire completion with four components addressing demographic data, participants' knowledge, attitudes and practices was used to collect data which was completed by a check list of infection control measures in the hospital. I designed it to examine interrelationships between the demographic variables of participants, their knowledge, attitudes and practice. It had 40 items divided into four sections: demographic data section with 10 items exploring the participants' social and professional status, section two of the knowledge on infections control measures with 9 items on principles of asepsis and self-caregiver-patient protection, section three on the participants' attitudes with 8 items exploring the participants feelings towards infection control, and the fourth one on the practice with 13 items exploring the qualities of nursing services offered to the population.

The literature review was generally reviewed on healthcare's attitudes, knowledge et practice in different angles of nursing services.

A Statistical Package for Social Scientists version 14.0 software (SPSS) was used to analyze the data which were presented as a frequency tables, pie charts, bar graphs. The score of the results were classified refer to the items' scored by participants in each section of variables. Ethical principles had been respected where an informed consent form was attached to the questionnaire, participants were given a choice whether to participate in the survey or not and the authorization to carry out the study was required from the Africa University research committee (AUREC), and Old Mutare Hospital Superintendent.

\section{Results}

The age of participants ranged from 27 to 55 years $(\bar{x}=39)$; Twenty-five (86.2\%) of the participants were females and four (13.8\%) were males and most of them (65.5\%) were qualified nurses. Of the 39 questionnaires which were distributed to the OMH's healthcare workers, 29 (74.3\%) returned correctly completed. None of the participants had been in service for a period which is less than one year, twelve $(41.4 \%)$ of them had been in service for more than 10 years, $11(37.9 \%)$ for a period of 5 to 10 years and $6(20.7 \%)$ for 1 year and 5

years. Most of the participants (58.6\%) had a diploma level whilst $10.3 \%$ had Degree level. Majority (48.3\%) of the participants had never attended any work- 
shop on Infection control measures (ICM), a significant number of the participants (41.4\%) assumed to be exposed/got HAIs whilst majority of them (58.6\%) were not and most of the participants (93.1\%) assumed not getting Hepatitis B Vaccine (Table 1).

The lowest score on the participant's knowledge were found in the ability to list the standards precautions for IC, to define the concept of HAI and the mode of transmission of HAIs (24.1\%, 34.5\%, 44.8\% respectively). On the other hand, the participants were able to list the materials that can transmit pathogens (62.1\%), the patients to be put in the Isolation room (75.9\%) and the body fluids from patients expected to be infectious (69.0\%) (Table 2).

Table 1. Demographic data of study participants.

\begin{tabular}{|c|c|c|}
\hline Characteristics & & Frequency $(\mathrm{N}=29)$ \\
\hline \multirow{2}{*}{ Age: } & Range & 27 years - 55 years \\
\hline & Mean & 39 years \\
\hline \multirow{2}{*}{ Sex: } & Female & $25(86.2 \%)$ \\
\hline & Male & $4(13.8 \%)$ \\
\hline \multirow{3}{*}{ Profession of participants: } & Nurse & $19(65.5 \%)$ \\
\hline & Nurse Aide & $8(27.6 \%)$ \\
\hline & Lab. Tech & $2(6.9 \%)$ \\
\hline \multirow{3}{*}{$\begin{array}{l}\text { Length of working } \\
\text { experience (years): }\end{array}$} & $1-5$ years & $6(20.7 \%)$ \\
\hline & 5 - 10 years & $11(37.9 \%)$ \\
\hline & More than 10 years & $12(41.4 \%)$ \\
\hline \multirow{4}{*}{$\begin{array}{l}\text { Workshop attended } \\
\text { on ICM: }\end{array}$} & None & $14(48.3 \%)$ \\
\hline & $1-2$ & $8(27.6 \%)$ \\
\hline & $3-5$ & $2(6.9 \%)$ \\
\hline & More & $5(17.2 \%)$ \\
\hline \multirow{2}{*}{ Have exposed/got HAIs: } & Yes & $12(41.4 \%)$ \\
\hline & No & $17(58.6 \%)$ \\
\hline \multirow{5}{*}{$\begin{array}{l}\text { Type of infection } \\
\text { exposed/got: }\end{array}$} & SARS only & $2(6.9 \%)$ \\
\hline & TB only & $2(6.9 \%)$ \\
\hline & Hepatitis only & $1(3.4 \%)$ \\
\hline & SARS, Skin \& Hepatitis & $4(13.8 \%)$ \\
\hline & Skin, TB, HIV \& Hepatitis & $3(10.3 \%)$ \\
\hline \multirow{2}{*}{ Hepatitis B Vaccinated: } & Yes & $2(6.9 \%)$ \\
\hline & No & 27 (93.1) \\
\hline
\end{tabular}


The Bivariate correlations by Spearman's rho revealed a week positive correlation (0.327) between the profession of the participants and their ability to give a definition of what is HAIs or not. The P-Value was greater than 5\% (0.084) then there were no statistically significant between these two variables (Table 3 ). Even though that all nurse aides were not able to define the concept of HAI, some nurses also did not define it (52.6).

The Bivariate correlations by Spearman's rho revealed a strong positive correlation (0.645) between the profession of the participants and the ability to explain how one can get HAIs $(\mathrm{P}=0.01)$ as the majority $(68.4 \%)$ of the nurses were able to explain how one can get HAIs, whereas all nurse aides and Lab Tech were not.

\section{Attitude of the participants towards infections control measures}

The majority of the participants, 27 (93.1\%) confirm be happy/willing to continue working as a HCWs. 2 (6.9\%) didn't say anything. Twenty-three (79.3\%) of the participants assumed that they fear that patients can infect them and Six (20.7\%) of them weren't. Majority of the participants $(58.6 \%)$ agree to be quarantined or their co-workers for the prevention and the control of HAIs purpose.

Majority of the participants (48.3\%), revealed that they feel anxious when they are taking care a patient with $\mathrm{TB}$ confirmed in the first week, or Hepatitis (HVB/HVC), $31.0 \%$, were so worry, $6.9 \%$ felt so sorry about them whilst $13.8 \%$ had no feelings at all (Figure 1).

Table 2. Knowledge towards infection control measures.

\begin{tabular}{|c|c|c|}
\hline Characteristics & $\begin{array}{c}\text { Yes } \\
\text { n (\%) }\end{array}$ & $\begin{array}{c}\text { No } \\
\text { n (\%) }\end{array}$ \\
\hline Definition of HAIs & $10(34.5 \%)$ & $19(65.5 \%)$ \\
\hline Infection control Program & $18(62.1 \%)$ & $11(37.9 \%)$ \\
\hline Transmission of HAIs & $13(44.8 \%)$ & $16(55.2 \%)$ \\
\hline standards precaution for IC & $7(24.1 \%)$ & $22(75.9 \%)$ \\
\hline Ability to list materials that can transmit pathogens & $18(62.1 \%)$ & $11(37.9 \%)$ \\
\hline Patients to be put in the Isolation room & $22(75.9 \%)$ & $7(24.1 \%)$ \\
\hline Body fluids from patients assumed to be infectious & $20(69.0 \%)$ & $9(31.0 \%)$ \\
\hline
\end{tabular}

Table 3. Correlation of the profession for participant and ability to define HAIs.

\begin{tabular}{|c|c|c|c|c|c|}
\hline & & \multicolumn{2}{|c|}{ Ability to define HAI } & \multirow{2}{*}{$\begin{array}{c}\text { Spearman's rho } \\
\text { Correlation } \\
\text { Coefficient }\end{array}$} & \multirow[b]{2}{*}{$\mathrm{P}$-value } \\
\hline & & $\begin{array}{c}\text { Yes } \\
\mathrm{n}(\%)\end{array}$ & $\begin{array}{c}\text { No } \\
\text { n (\%) }\end{array}$ & & \\
\hline \multirow[t]{4}{*}{ Profession } & Nurse & $9(47.3)$ & $10(52.6)$ & \multirow{4}{*}{0.327} & \multirow{4}{*}{0.084} \\
\hline & Nurse Aide & 0 & $8(100)$ & & \\
\hline & Lab. Tech & $1(50)$ & $1(50)$ & & \\
\hline & N) & 10 & 19 & & \\
\hline
\end{tabular}




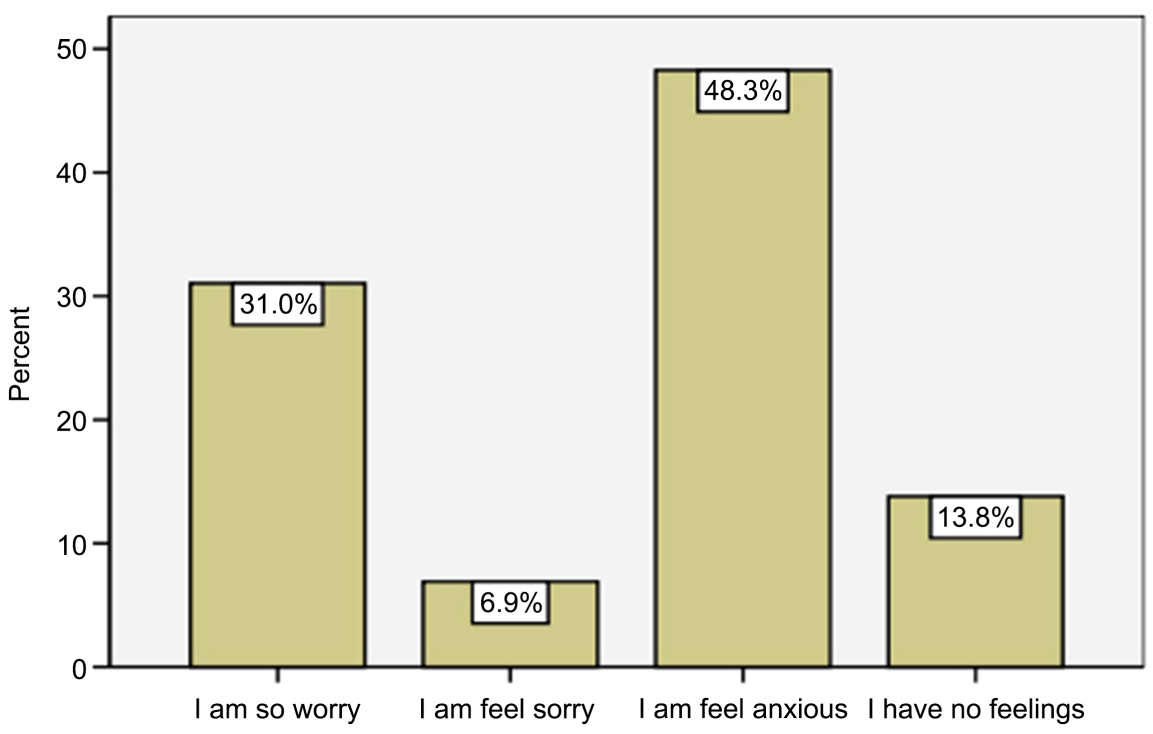

Figure 1. HCWs feelings when taking care of a patient with TB confirmed in the first week, or Hepatitis.

\section{Practice of study participants towards infection control measures}

Majority (58.6\%) of the participants assumed not to recap the needle after its use, other do it by mistake (37.9\%) and other confirmed to do it (3.4\%) and Majority $(79.3 \%)$ of the participants assumed to be washing their hands and $75.9 \%$ were aware that the Infection control manual guideline was available in their workplace.

Majority of the participants (37.93\%) highlighted that Hand washing properly; Wearing caps, masks and shoe covers; Regular vaccination of HCW and Isolation of infected patient are the most effective method to prevent HAIs, $20.69 \%$ emphasized that Proper management of infectious waste could be the most effective method, $10.34 \%$ said that Prudent use of antibiotics could be the most effective method, $6.9 \%$ highlighted that Visitor management could be the most effective while $24.14 \%$ dad no idea of what could be the most effective method to prevent HAIs (Figure 2).

\section{Discussion}

We would never find nosocomial infections in the hospitals if a proper infection control practice was carried out by healthcare practitioner. Breaching the infection control guidelines in the hospital is the major cause of the transmission of nosocomial infections among healthcare givers and their patients. Thus, to limit this, continuance education for healthcare givers on infection control measures is needed.

None of the participants had been in service for a period which is less than one year, simply means that all the participants, had enough experience with the hospital environment to be able to have sufficient knowledge to control the HAIs as the majority of them (41.4\%) had been in service for more than 10 years 


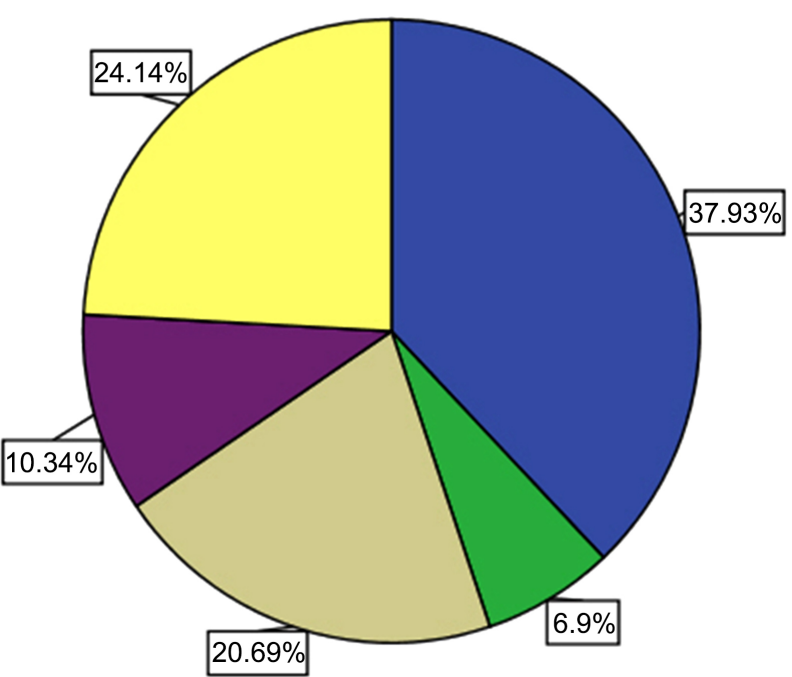

Hand washing properly: Wearing caps, masks and shoe covers: Regular vaccition of $\mathrm{HCW}$, Isolation of infected patient

Visitor management

Proper management

of infectious waste

Prudent use of antibiotics

$\square$ No idea

Figure 2. The most effective method to prevent HAIs.

(Table 1). But the currently study shows a deficiency knowledge and practice among the participant, this concurs a study done by Hakim, Mohsen and Bakr, 2014 which revealed that their training and their experience in healthcare service were not meaningfully related to their knowledge, attitude and practice scores, except for nurses with longer experience, who had presenting an acceptable knowledge on waste management [5].

A Cross tabulation between the Profession of participants and the Workshop attended on infection control measures revealed that the majority $(52.6 \%)$ of the nurses, $37.5 \%$ of the nurse's aide and 50\% Lab. Tech. had never attended any workshop on ICM, hence can contribute to a deficiency in the practice and control of HAIs. This Concurs with a study done by Chipfuwa et al. 2014 where they highlighted that the problem is that they don't give opportunities of attending workshops to the junior nurses who do more nursing care activities in service [3] whereby the findings on their study reveal that a quite significant number of nurses (68\%) did not attend infection control workshops with the majority of these $(97 \%)$ being junior and senior nurses who are always providing day to day nursing care. The study reveals also that there was no significant association between the professions of the participants and their workshop attendance on infection control $(\mathrm{P}=0.773)$, thus a systematic in-service education on infection control measures for all healthcare workers would be recommended to keep them updated with current knowledge as well as by providing them with adequate material resources.

The majority of the participant, 27 (93.1\%) assumed that they do not get Hepatitis B Vaccine. 2 (6.9\%) of the participants assumed to be having Hepatitis B Vaccine (Table 1). This contrast the findings of the study done by Fashafsheh et al. 2015, whereby majority of the participants in their study assumed to have hepatitis $B$ vaccine [6], emphasizing the hospitals policies to vaccinate every new 
nurse employed to manage the exposition on blood borne pathogens and needle stick, thus this was recommended also to Old Mutare Hospital, as the currently study had shown that 12 (41.4\%) of the participants assumed to be exposed/got HAIs and 27.5\% have been exposed to Hepatitis (HBV/HVC) and other problem.

Majority of the participants, 19 (65.5\%) shown a lack of knowledge, as they were not able to give the definition (Table 2), only 10 (34.5\%) of the participants have managed to define what is HAIs and the findings reveal a week positive correlation ( $\mathrm{P}=0.327)$ between the profession of the participants and their ability to give a definition of what is HAIs or not (Table 3 ), thus they were no relationship between their ability to define what is HAIs of the participants and their professional status, with $\mathrm{P}$ value 0.084 . This contrast the findings of Samaila et al. 2015, in their study whereby majority of the respondents $57.5 \%$ were able to define correctly the concept of nosocomial infection and highlighted that regular in-service training program for staff was needed [6]. The findings shown insufficient, unfavorable and unsafe participant's knowledge on standard precaution to the expected standard as the statistics revealed that majority $22(75.9 \%)$ of the participants did not know the standards precaution for infection control (Table 2), hence can contribute to a deficiency practice and control of HAIs. This is in line with Yakob et al. 2015 in their study whereby healthcare works 57 (42.2\%) think to apply standards precautions always [7].

The findings revealed also that majority of the participants (62.1\%) know that the infection control program exist in their hospital, even though, there was a few number (37.9\%) of them who don't know the existence of that program and this can contribute to a deficiency service in the prevention and control of HAIs, as Chipfuwa et al. 2014 assumed that hospital-acquired infections can be increased by lack of knowledge among nurses [3]. Majority (55.2\%) of the participants had a deficiency knowledge on how one can get HAIs, thus this can be a challenge in the prevention and control of HAIs as they do not know how one cat get it, later will be contracting the disease. The current study revealed a strong positive correlation (0.645) between the profession of the participants and their ability to explain how one can get HAIs (Table 4) and this had a greater statistically significant $(\mathrm{P}=0.01)$. Thus, these HCWs need in service training and to be participate in the workshop of infection control so that they can update their knowledge, this is in line with Fashafsheh et al. 2016, recommending the continuing in-service educational programs to update the nurse's knowledge and practice by emphasizing the importance of following the updated evidence-based practices of infection control [8].

Twenty-two (75.9\%) of the participants were able to list out whom patients to be put in the isolation room, like Patients with TB, Cholera, Plague, Smallpox, viral hemorrhagic fever (like Ebola), SARS, Flu that can cause a pandemic. Seven (24.1\%) of the participants were not able. Also, twenty (69.0\%) of the participants were able to list out the body fluids from patients expected to be infectious like Blood, Nasal discharge, Saliva, Vomitus, Feces, Urine, Sweat, Vaginal secretion, 
Table 4. Correlation of the Profession of the participants and their ability to explain how one get HAIs.

\begin{tabular}{|c|c|c|c|c|c|}
\hline & & \multicolumn{2}{|c|}{$\begin{array}{l}\text { Able to explain how } \\
\text { one get HAI }\end{array}$} & \multirow{2}{*}{$\begin{array}{c}\text { Spearman's rho } \\
\text { Correlation } \\
\text { Coefficient }\end{array}$} & \multirow{2}{*}{ P-Value } \\
\hline & & $\begin{array}{c}\text { Yes } \\
\text { n (\%) }\end{array}$ & $\begin{array}{c}\text { No } \\
\text { n (\%) }\end{array}$ & & \\
\hline \multirow[t]{4}{*}{ Profession } & Nurse & 13 & 6 & \multirow{4}{*}{$\left.0.645{ }^{* *}\right)$} & \multirow{4}{*}{0.01} \\
\hline & Nurse Aide & 0 & 8 & & \\
\hline & Lab. Tech & 0 & 2 & & \\
\hline & & 13 & 16 & & \\
\hline
\end{tabular}

${ }^{* *}$ Correlation is significant at the 0.01 level (2-tailed).

Sputum. Nine (31.0\%) of the participants were not able, also this study revealed a strong participants' knowledge on personal protection against HAIs as they were able to know whom to be putting in the isolation room and the body fluid that can transmit infections, but in service training is need reach full compliance as a few of them had presented a poor knowledge.

Majority of the participants 14 (48.3\%), revealed that they feel anxious when they are taking care patients with TB confirmed in the first week, or Hepatitis (HVB/HVC), 9 (31.0\%) were worried, 2 (6.9\%) felt sorry and Four (13.8\%) do not have any feelings (Figure 1). This concurs with the study done by Yakob et al., 2015, highlighting that the overall infection control measures by nurses' attitudes were strongly predicted by their professional obligation of care, as several healthcare workers were worried of getting HIV/AIDS while caring for patients in their work place [7].

The majority of the participants, 27 (93.1\%) confirm that they are Happy/willing to continue working as a HCWs whilst $2(6.9 \%)$ did not say anything. These findings are in contrast with Kanjee et al., 2011, in their survey asthe result revealed fear among staff getting tuberculosis (49.1\%), accusing a careless to the hospital for not protecting them from TB infections and $42.9 \%$ had showed a less willing to continue working as a healthcare provider because of staff TB/MDR-TB/XDR-TB deaths [9].

All the participants, 29 (100\%) assumed to be comfortable with the new policy of screening TB every HCW. This contrast the findings of Sekaiin 2015 at Mpilo Hospital as HCWs were not interested to be screened from TB because ofstigma, inadequate knowledge and fear of losing their employment [10].

Twenty-three (79.3\%) of the participants assumed that they fear that patients can infect them and Six (20.7\%) of them were not. This is in line with the findings of Angelillo et al. 1999, whereby nurses were supporting a discrimination of patients presenting HIV/HCV/HBV to be treated in a specialist Centre by fear of contracting infection from them as most of them (93.4\%) argue that it was necessary to know if the patient was seropositive or not, and believe that infection control measures should be stringent more for VIH than for hepatitis B virus 
(40.3\%) to prevent the HIV transmission [11].

Majority of the participants, 17 (58.6\%) agree to be quarantined or their co-workers for the prevention and control of HAIs purpose. 9 (31.0\%) had strongly agreed. 3 (10.3\%) had disagreed to be quarantine or their co-workers. This contrast Tzeng (2004) whereby the results revealed a sense of social discrimination among nurses if they were told to be quarantined after care of SARS's patients [12].

Therefore, the currently study had revealed a fair attitude towards infection control among Old Mutare Hospital HCWs as the score from all the variables was ranged between $79.3 \%$ to $100 \%$, even though that few of the participants had showed a poor attitude which reveal their poor knowledge towards infection control.

Eleven (37.93\%) of the participants highlighted that Hand washing properly; Wearing caps, masks and shoe covers; Regular vaccination of HCW and Isolation of infected patient were the best way to prevent HAIs while Six (20.69\%) highlighted that the proper management of infectious waste could be the effective one. Three (10.34\%) highlighted that prudent use of antibiotics could be the best method to be used in the prevention of HAIs. Two (6.9\%) highlighted that Visitor management could be used whilst Seven $(24.14 \%)$ had no idea of what could be the best way to prevent HAIs (Figure 2). Thus the findings revealed that majority of the participant were aware the best way to prevent HAIs, even though some of them were not; this concurs the findings of Samaila et al. in their study, whereby participants (46.9\%) were aware the proper ways of preventing HAIs, thus highlighted that hospital staff deserve regular in-service training program and practice of universal precaution [6].

The findings revealed, although that the majority (58.6\%) of the participants assumed not to recap the needle after its use, there are other part of the participants who still do it by mistake (37.9\%) and other confirmed to do it (3.4\%), hence this will be one of the factors that these healthcare works can get the HAIs. This tallied with a study done by Yakob et al. 2015 among Mizan-Aman General Hospital Workers whereby needles were also been recapped by some healthcare works $84(62.5 \%)$ after being used immediately [7]. So, in service training is needed to update their knowledge so that they can have a safe practice and prevent themselves towards HAIs.

Majority (79.3\%) of the participants assumed to be washing their hands, this concurswith the study done by Yakob et al. 2015, where the findings also revealed that majority of the participants were doing so prior patients' examination [7]. The contrast on these findings occurs in the study done by Tolulope et al. 2017, whereby he mentioned that almost the half of the participants wash always hands before examining their patients [13]. The HCWs are supposed to take hands washing precautions as a serious focal point while taking care patients and washing hands standard precautions to be available in all health sector, moreover, "The practice of standard safety precaution with regards se- 
quencing of hand washing in course of service provision is vital to halting transmission of pathogen to other patients as well as the health care workers" [13].

The currently study revealed also a fair practice among the participants as the score from the variables ranged from $58.6 \%$ and $79.3 \%$ towards infection control. Therefore, in service education and workshop participation is needed to attain full compliance.

\section{Recommendations}

The following are the recommendations that emanated from the study:

1) Old Mutare Hospital administration have to come up with strategies of updating the knowledge of the HCWs on infection control measures, especially the nurse's aide such as in-service training and workshop.

2) Encouraging the head of the departments to put posters and manual guidelines of infection control measures where every healthcare worker can access it so that they can follow the standards and strategies of MOHCC.

3) Old Mutare Hospital administration have to come up with a policy that emphasize that every HCWs have to get Hepatitis B Vaccine and for the new recruit to have it before being exposed.

4) To come up with an active committee of infection control that will call all HCWs to be involved and participate in, so that everyone is aware with the program and participate in the control and prevention of HAIs.

5) Further research should be conducted for assessing the knowledge, attitudes and practices towards infection control measures among HCWs including Doctors, Dentists and Radiographers.

\section{Conclusion}

This study had revealed a poor knowledge among HCWs, especially the nurse's aide, their attitude and practices were impartially good as in all variables the participants had scored over $50 \%$ towards their attitude and their practices. Thus, in-service training and workshop program had been highlighted and recommended to update their knowledge and improve their practice to attain full compliance.

\section{Limitation}

This study has some limitations. The study was done in one rural hospital with a small population and the author did not test the questionnaire's validity or reliability.

\section{Conflicts of Interest}

The authors declare no conflicts of interest regarding the publication of this paper.

\section{References}

[1] Lucy, A., Miriam, W., Cecilia, M. and Peter, B. (2015) Prevalence of Bacterial No- 
socomial Infections in Matibabu Foundation Hospital and Ukwala Sub County Referral Hospital in Siaya County. http://medcraveonline.com/JBMOA/JBMOA-02-00042.php

[2] Chitimwango (2017) Knowledge, Attitudes and Practices of Nurses in Infection prevention and Control within a Tertiary Hospital in Zambia. http://scholar.sun.ac.za/handle/10019.1/101156

[3] Chipfuwa, T., Manwere, A. and Shayamano P. (2014) Barriers to Infection Prevention and Control (IPC) Practice among Nurses at Bindura Provincial Hospital, Zimbabwe. https://pdfs.semanticscholar.org/fa46/bb7dc7c6a6265b6d37e1bf97293101936c7c.pdf

[4] Creedon (2005) Infection Control: Behavioral Issues for Healthcare Workers. Clinical Governance an International Journal, 11, 316-325.

[5] Hakim, S.A., Mohsen, A. and Bakr, I. (2014) Knowledge, Attitudes and Practices of Health-Care-Providers towards Waste Management at Ain Shams University Hospital, Cairo. https://doi.org/10.26719/2014.20.5.347

[6] Samaila, A., Joshua, A., Danjuma, A., Mohammed, U., Omoniyi, O. and Haruna, D. (2015) Knowledge of Healthcare Workers on Nosocomial Infection in Selected Secondary Health Institutions in Zaria, Nigeria.

http://pubs.sciepub.com/jpm/3/1/1/.

[7] Yakob, E., Lamaro, T. and Henok, A. (2015) Knowledge, Attitude and Practice towards Infection Control Measures among Mizan-Aman General Hospital Workers, South West Ethiopia.

https://www.omicsonline.org/open-access/knowledge-attitude-and-practice-toward s-infection-control-measures-among-mizanaman-general-hospital-workers-southwest-ethiopia-2161-0711-1000370.php?aid=61015.

[8] Fashafsheh, I., Ayed, A., Faeda, E. and Harazneh, L. (2015) Knowledge and Practice of Nursing Staff towards Infection Control Measures in the Palestinian Hospitals. https://files.eric.ed.gov/fulltext/EJ1083751.pdf

[9] Kanjee, Z., Catterick, K., Moll, A., Amico, K. and Friedland, G. (2011) Tuberculosis Infection Control in Rural South Africa: Survey of Knowledge, Attitude and Practice in hospital staff. https://www.ncbi.nlm.nih.gov/pubmed/21978608

[10] Sekai, L. (2015) Health Worker TB Screening Uptake at Mpilo Central Hospital, Bulawayo, Zimbabwe. Published in Johannesburg, South Africa by Wangai H. September 2016.

https://aricjournal.biomedcentral.com/articles/10.1186/s13756-016-0153-0

[11] Angelillo, I., Mazziotta, A. and Nicotera, G. (1999) Nurses and Hospital Infection Control: Knowledge, Attitudes and Behaviour of Italian Operating Theatre Staff. University of Catanzaro Magna Græcia, Italy. https://pdfs.semanticscholar.org/28ad/e0a11484c8a5a743fb59224666c7f4210f0e.pdf

[12] Tzeng, H. (2004) Nurses' Professional Care Obligation and Their Attitudes towards SARS Infection Control Measures in Taiwan during and after the 2003 Epidemic. https://www.ncbi.nlm.nih.gov/pubmed/15176641

[13] Tolulope, O., Zuwaira, I., Danjuma, A., Tinuade, O. and Moses, P. (2017) Assessment of Knowledge and Practice of Standard Safety Precautions among Primary Health Care Workers in Plateau State North Central Nigeria. http://ssjournals.com/index.php/ijbr/article/download/4028/2761 